\title{
Perirenal and renal subcapsular haematoma as presenting symptoms of polyarteritis nodosa
}

\author{
M. Schlesinger ${ }^{1}$, S. Oren ${ }^{2}$, M. Fano ${ }^{2}$ and J.R. Viskoper ${ }^{2}$ \\ Departments of 'Immunology and ${ }^{2}$ Medicine, Barzilai Medical Center, Ashkelon 78306, Israel.
}

\begin{abstract}
Summary: Two young men, were hospitalized due to acute massive blood loss with left abdominal flank pain. In both cases renal angiography showed signs of a haemorrhagic event in the left kidney, perirenal in one and subcapsular in the other. Microaneurysms indicated a diagnosis of polyarteritis nodosa, supported by renal biopsy in one case. Renal haemorrhage is an infrequent presentation of polyarteritis nodosa. Furthermore, one patient suffered also from familial Mediterranean fever, and is the fifth reported case with this combination of diseases.
\end{abstract}

\section{Introduction}

In 1908 Schmidt described perirenal haematoma caused by rupture of microaneurysms in a patient with polyarteritis nodosa (PAN). ${ }^{1}$ However, perirenal or subcapsular haematoma as a presenting symptom of PAN is rare.

In this communication, we describe 2 patients, one with familial Mediterranean fever (FMF), in whom kidney haemorrhage was the presenting symptom of PAN. The importance of early recognition of this rare, but potentially life-threatening complication, is emphasized.

\section{Case reports}

\section{Case 1}

A 26 year old male was hospitalized because of general weakness, perspiration and severe pain in the left loin. He experienced a short event of diplopia and ptosis of the right lid which, apparently, remained undiagnosed.

At admission, the patient was pale, restless and sweating. Peripheral pulse was $150 / \mathrm{min}$, regular. Supine blood pressure was $140 / 80 \mathrm{mmHg}$. Standing blood pressure was $80 / 50 \mathrm{mmHg}$. An abdominal mass was palpated in the left lower abdominal quadrant without signs of abdominal rigidity.

Laboratory investigations revealed haemoglobin $12.6 \mathrm{~g} / \mathrm{dl}$, which fell to $10.5 \mathrm{~g} / \mathrm{dl}$ after two hours, a leucocytosis and thrombocytosis but normal biochemistry and coagulation tests. Complement component levels were normal and LE cells were not

Correspondence: J.R. Viskoper, M.D.

Accepted: 7 March 1989 seen. Anti-nuclear factor (ANF) was absent, Australian antigen, Rose Waaler and latex agglutination tests were negative. Urinalysis showed red and white cells but no casts. Abdominal X-ray showed a huge mass in the left lower quadrant. Intravenous urography showed a pear-formed mass at the lower pole of the left kidney, compressing the bladder and causing a deviation to the right.

The patient received blood transfusion and abdominal angiography was performed in view of the presumed renal haemorrhage. This showed multiple microaneurysms in the superior mesenteric artery and in both renal arteries (Figure 1) consistent with the diagnosis of PAN.

Because of continuous bleeding, the perirenal haematoma was drained. Biopsy of the lower pole of the left kidney showed an area of haemorrhage and infarction. The post-operative course was uneventful and treatment with cyclophosphamide and corticosteroids was instituted.

\section{Case 2}

A 21 year old male soldier, born in Tunis, was admitted because of severe pain in the left loin. His past history was remarkable for frequent attacks of abdominal pain and arthralgia with fever lasting 2-3 days; elevated ESR and plasma fibrinogen levels, which were diagnosed as FMF. Two of his siblings were also known to suffer from FMF.

Two weeks prior to the present hospitalization, he had been hospitalized because of severe pain in his left loin, weakness and tachycardia of $100 / \mathrm{min}$. The blood pressure was $140 / 90 \mathrm{mmHg}$. The laboratory examination revealed haemoglobin $9.0 \mathrm{~g} / \mathrm{dl}$, ESR of 140 in one hour. The urine contained protein and red cells. 


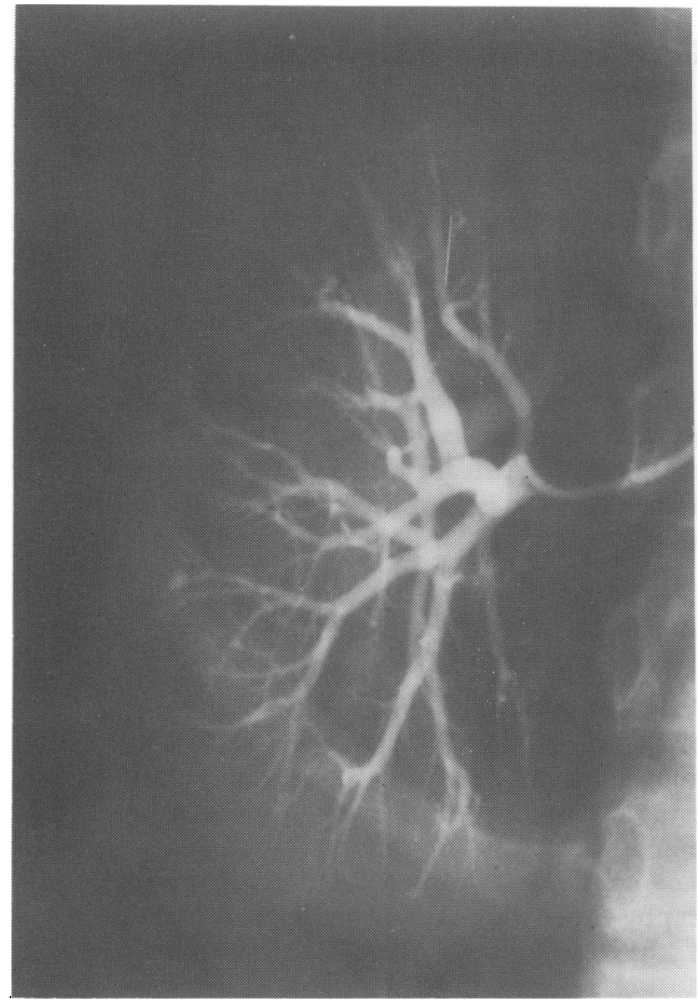

Figure 1 Angiography of the left kidney of case 1, demonstrating microaneurysms of the renal arteries.

The antistreptolysin titre was $1 / 3200$. Rectal and buccal biopsies were negative for amyloid, and muscle biopsy did not reveal vasculitis. Gastrointestinal tract evaluation did not reveal any bleeding source and a diagnosis of poststreptococcal glomerulonephritis was presumed.

On the present admission, he showed signs of acute bleeding with sudden decrease of haemoglobin from 8.8 to $6.5 \mathrm{~g} / \mathrm{dl}$, tachycardia and orthostatic hypotension.

Physical examination revealed a palpable spleen and tenderness of the left lower abdominal quadrant. Biochemistry and coagulation tests were normal. Rose Waaler, latex agglutination and Australian antigen results were negative.

Intravenous urography showed a mass in the lower pole of the left kidney which compressed the lower calyces and caused lateral deviation of the kidney. Ultra-sound examination and computerized tomography supported a diagnosis of subcapsular haematoma. Subsequently, renal angiography was performed revealing microaneurysms in both kidneys (Figure 2).

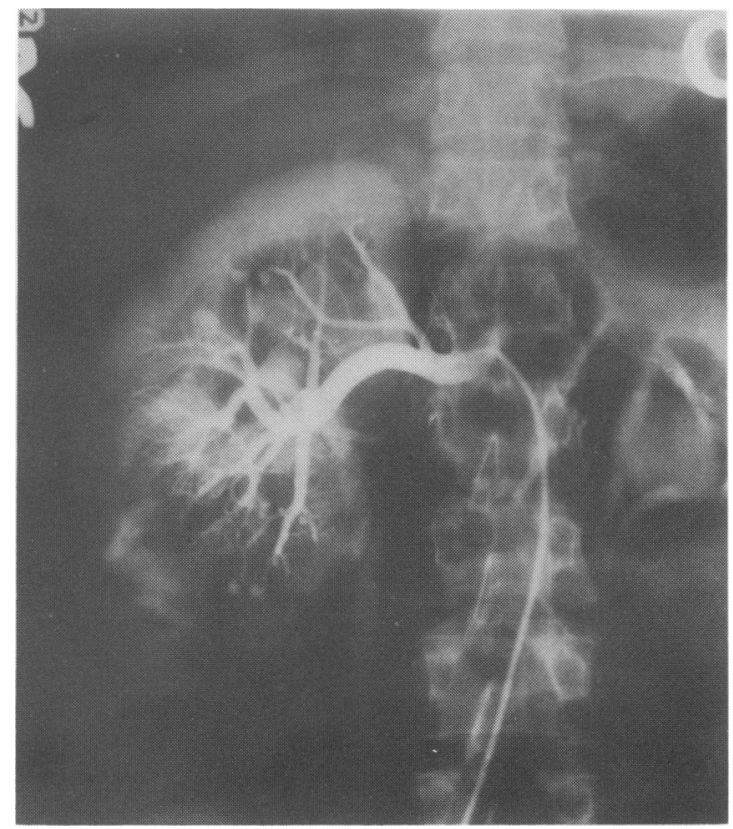

Figure 2 Angiography of the right kidney of case 2, demonstrating microaneurysms of the renal arteries.

In the absence of evidence of systemic lupus erythematosus (SLE) it was presumed that the basic disease causing the microaneurysms was PAN. No intervention was needed, and with conservative treatment the bleeding stopped; prednisone and cyclophosphamide were given. Renal function remained intact.

\section{Discussion}

Since the first description of perirenal haematoma due to $\mathrm{PAN}^{1}$ bleeding in other organs has also been shown to occur in PAN. ${ }^{2-4}$ The two patients reported here presented with renal haemorrhage as the first manifestation of the disease. This complication of PAN is rare, ${ }^{5,6}$ and delay in making the correct diagnosis is particularly likely to occur when bleeding is the first manifestation of PAN. Another difficulty with this condition is that ideally the diagnosis should be based upon histological confirmation of vessel involvement. However, if the biopsy is taken from an uninvolved area, there is a chance that no characteristic histologcal finding can be observed. ${ }^{6,7}$ On the other hand, biopsy from an involved area in the kidney may cause serious renal haemorrhage. Even if a successful kidney biopsy is obtained, it needs to contain renal arterioles in order to quantify vessel changes of vasculitis, as glomerular changes per se are not pathognomonic. ${ }^{7}$ 
These considerations stress the importance of renal angiography, as an alternative diagnostic procedure, to show microaneurysms in the small and mediumsized vessels. ${ }^{5,8}$ Microaneurysms are also seen in rheumatoid vasculitis. SLE, malignant hypertension and Gram-negative sepsis, ${ }^{5,7}$ conditions excluded in the present cases. Surgical intervention was needed only in case 1 , while in case 2 , bleeding stopped spontaneously. An alternative approach might be gel-foam embolization of the bleeding artery. ${ }^{6}$

The possibility of renal haemorrhage in PAN should be kept in mind after excluding alternative possibilities which may arise, such as streptococcal induced glomerulonephritis. ${ }^{9,10}$ In our case, the major

\section{References}

1. Schmidt, J.E. Uber periarteritis nodosa. Beitr Path Anat 1980, 43: 455-459.

2. Fullingborg, J.A. Traumatic rupture of the spleen in periarteritis nodosa. Acta Chir Scand 1985, 151: 85-87.

3. Martinez, V., Mardomingo, P., Estevez, A. et al. Hepatic subcapsular hematoma and polyarteritis nodosa. $A n$ Med Interna (Spain) 1985, 214187.

4. Huttunen, R., Seppala, A. \& Mokka, R. Spontaneous rupture of the liver and the spleen. Surgery 1975, 77: 722-725.

5. Dornfield, L., Lecky, J.W. \& Peter, J.B. Polyarteritis and intrarenal renal artery aneurysms. JAMA 1971, 215: 1950-1952. findings that suggested renal haemorrhage were flank pain and signs of haemorrhagic shock. Although in the second case the severe bleeding occurred 2 weeks after the initial complaint, it may be concluded, retrospectively, that occult bleeding started at his first hospitalization. The urine did not contain casts and no azotaemia or oedema were observed to support a diagnosis of acute nephritis.

The combination of FMF and PAN is intriguing. It has been described before only in four cases, three of which were from Israel. ${ }^{6}$ It has been suggested that the combination is too frequent to be attributed to mere chance. However, the pathophysiological implications of this association are still unknown.

6. Sachs, D., Langeritz, P., Morag, B. et al. Case report polyarteritis nodosa and familial Mediterranean fever. Br J Rheumatol 1987, 26: 134-140.

7. Fink, C.W. Vasculitis Pediatr Clin North Am 1981, 33: 1203-1219.

8. Reinold, E.W., Weinber, A.G., Fink, C.W. et al. Polyarteritis in children. Am J Dis Child 1976, 130: 534-541.

9. Fordham, C.C., Epstein, F.H., Huffines, W.D. et al. Polyarteritis and acute post-streptococcal glomerulonephritis. Ann Intern Med 1964, 61: 89-97.

10. Dawson, D. Acute periarteritis nodosa with chronic glomerulonephritis. Arch Pathol 1959, 68: 651-656. 